\title{
Call for Special Issue Papers: Food Safety in China: Current Practices and Future Needs
}

\section{Deadline for Manuscript Submission: September 30, 2020}

\author{
Guest Editors: Min Yue, DVM, PhD; Zhejiang University; Houhui Song, BAg, MS, PhD; Zhejiang A\&F University; \\ Li Bai, MD, PhD; China National Center for Food Safety Risk Assessment
}

Foodborne Pathogens and Disease is currently seeking manuscripts with a dedicated focus on "Food Safety in China: Current Practices and Future Needs." Original research papers and reviews are welcome. Foodborne Pathogens and Disease spans an array of issues from "farm-to-fork," and the Journal bridges the gap between science and policy to reduce foodborne illness worldwide

Topics of interest for reviews and research articles include, but are not limited to:

- Overall food safety situations and future needs for control of pathogenic microbes (bacteria, viruses and parasites) along the food production chain in China.

- Prevalence of pathogens: 1) along the food chain in particular foods, 2) in particular production steps, or 3) in specific regions focusing on special problems.

- Advances in methodology, particularly rapid and high-throughput technologies for detection and source tracking.

- Advanced technologies to mitigate food safety risks.

- Risk management or mitigation technologies in particular food production systems (or for specific food products).

- Antimicrobial resistance in food animals and their transmission to humans

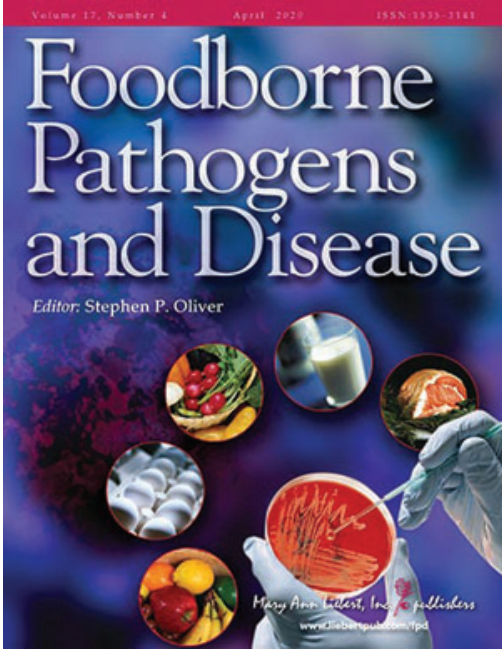
via foods.

- Integrated food-chain (farm-to-fork) studies for microbial risk.

Advantages of publishing in the Journal include:

- Rapid, high-quality peer review and editorial attention.

- Immediate deposit to PubMed and other indexing services upon online publication.

- Exposure to thousands of thought-leaders in your field, maximizing readers, citations, and downloads.

- Fast Track online-ahead-of-print publication.

- Global availability in over 170 countries.

- Open Access publication options.

- Competitive author benefits program.

Authors may vet ideas directly with guest editors via e-mail before submitting. Please refer our website for Instructions for Authors and manuscript submission at www.liebertpub.com/fpd We look forward to receiving your manuscripts and to your active participation in the Journal!

Questions or pre-submission queries? Please contact the Guest Editors: Min Yue, DVM, PhD: myue@zju.edu.cn Houhui Song, BAg, MS, PhD: songhh@zafu.edu.cn Li Bai, MD, PhD: lilibaisun@126.com

\section{Visit the Instructions for Authors: www.liebertpub.com/fpd}

\section{Submit your paper for peer review online: https://mc.manuscriptcentral.com/fpd}

Mary Ann Liebert, Inc., publishers, 140 Huguenot Street, New Rochelle, NY 10801, USA. 